\title{
Pinellia ternata lectin exerts a pro-inflammatory effect on macrophages by inducing the release of pro-inflammatory cytokines, the activation of the nuclear factor- $\kappa B$ signaling pathway and the overproduction of reactive oxygen species
}

\author{
HONG-LI YU ${ }^{1-3 *}$, TENG-FEI ZHAO ${ }^{1 *}$, HAO WU $^{1-3}$, YAO-ZONG PAN $^{1}$, \\ QIAN ZHANG $^{1}$, KUI-LONG WANG ${ }^{1}$, CHEN-CHAO ZHANG ${ }^{1}$ and YANG-PING JIN ${ }^{1}$ \\ ${ }^{1}$ School of Pharmacy, ${ }^{2}$ Jiangsu Key Laboratory of Chinese Medicine Processing, Nanjing University of Chinese Medicine, \\ Nanjing, Jiangsu 210023; ${ }^{3}$ Engineering Center of State Ministry of Education for Standardization \\ of Chinese Medicine Processing, Nanjing, Jiangsu 210023, P.R. China
}

Received January 7, 2015; Accepted August 13, 2015

DOI: $10.3892 /$ ijmm.2015.2315

\begin{abstract}
Pinellia ternata (PT) is a widely used traditional Chinese medicine. The raw material has a throat-irritating toxicity that is associated with the PT lectin (PTL). PTL is a monocot lectin isolated from the tubers of PT, which exhibits mouse peritoneal acute inflammatory effects in vivo. The present study aimed to investigate the pro-inflammatory effect of PTL on macrophages. PTL $(50 \mu \mathrm{g} / \mathrm{ml})$-stimulated macrophages enhanced the chemotactic activity of neutrophils. PTL $(50,100,200$ and $400 \mu \mathrm{g} / \mathrm{ml})$ significantly elevated the production of cytokines [tumor necrosis factor- $\alpha$ (TNF- $\alpha)$ , interleukin (IL)-1 $\beta$ and IL-6]. PTL (25, 50 and $100 \mu \mathrm{g} / \mathrm{ml})$ induced intracellular reactive oxygen species (ROS) overproduction. PTL also caused transfer of $\mathrm{p} 65$ from the macrophage cytoplasm to the nucleus and activated the nuclear factor- $\mathrm{KB}$ (NF- $\mathrm{KB}$ ) signaling pathway. Scanning electron microscope images revealed severe cell swelling and membrane integrity defection of macrophages following PTL $(100 \mu \mathrm{g} / \mathrm{ml})$ stimulation, which was also associated with inflammation. PTL had pro-inflammatory activity, involving induced neutrophil migration, cytokine release, ROS overproduction and the activation of the NF- $\mathrm{KB}$ signaling pathway, which was associated with the activation of macrophages.
\end{abstract}

Correspondence to: Professor Hao Wu, School of Pharmacy, Nanjing University of Chinese Medicine, No. 138, Xianlin Avenue, Nanjing, Jiangsu 210023, P.R. China

E-mail: whao5795@126.com; whao5795@163.com

${ }^{*}$ Contributed equally

Key words: Pinellia ternata lectin, macrophage, cytokine, neutrophil migration, reactive oxygen species production, nuclear factor- $\kappa \mathrm{B}$

\section{Introduction}

As sugar-binding proteins, lectins are highly specific for their sugar moieties and ability to agglutinate cells (1). Lectins are widely distributed in microorganisms, viruses and animals that are capable of mediating a series of biological recognition events (2-4). Lectins from plants have been well studied, showing severe pro-inflammatory effects in vivo and in vitro (5-7).

Certain plant lectins are highly toxic in clinical and animal experiments, accompanied by neutrophil migration at inflammatory sites. Neutrophil migration into inflamed tissues is an important hallmark of acute inflammation, and resident macrophages have a critical role in triggering immune response and in inducing neutrophil infiltration at the early stage of damage (8-14). Inflammatory response is a complex phenomenon that involves vascular and cellular events. In cellular events, lymphocyte recirculation depends on the response to a cell surface signal (15-17).

Arum maculatum agglutinin, a plant lectin, exhibits pro-inflammatory activity and induces neutrophil migration by stimulating resident macrophages (18). Furthermore, our previous study revealed that certain lectins from plants in the Araceae family also had such pro-inflammatory effects, and that a lectin purified from Arisaema erubescens (Wall.) Schott induced rat paw edema and neutrophil migration, possibly via the release of inflammatory mediators from macrophages (19).

Pinellia ternata (PT) (Araceae) has been widely used as a traditional Chinese medicine to treat excessive phlegm and emesis. The raw material has a throat-irritating toxicity, which can be alleviated by being immersed in alum solution or boiled for a long time. Such toxicity is associated with PT lectin (PTL) (20).

PTL was isolated to continue the study on the pro-inflammatory effects of lectins from the Araceae family. In addition, the pro-inflammatory effects of PTL on the activation of macrophages, and the possible involvement of PTL-stimulated resident macrophages in neutrophil recruitment were 
evaluated, aiming to understand the toxicity mechanism of PTL and to provide evidence for detoxification of PT.

\section{Materials and methods}

Animals. Male Institute of Cancer Research (ICR) mice obtained from the animal facilities of Nanjing Medical University (Nanjing, Jiangsu, China) were housed $(n=5)$ in a temperature-controlled room and received water and food ad libitum. Animal welfare and experimental procedures were strictly in accordance with the Guide for the Care and Use of the Laboratory Animals (US National Research Council, 1996) and the associated ethics regulations of Nanjing University of Chinese Medicine (Nanjing, Jiangsu, China).

Plant material. The tubers of PT were collected from Jiangsu Province (China) with the help of Taizhou Gaogang Pieces Factory Co., Ltd., (Jiangsu, China) on May 25, 2012. The fresh plant was identified by Professor Chungen Wang (Nanjing University of Chinese Medicine).

Apparatus, chemicals and reagents. Mini protean cell and semi-dry transfer cell was supplied by Bio-Rad Laboratories (Hercules, CA, USA). HiPrep ${ }^{\mathrm{TM}}$ Phenyl FF, HiTrap ${ }^{\mathrm{TM}}$ Q FF, HiTrap $^{\mathrm{TM}}$ desalting and AKTA purifier were supplied by GE Healthcare (Uppsala, Sweden). Scanning electron microscope (SEM) was supplied by Nikon (Tokyo, Japan). Fluorescence microplate reader was supplied by BioTek Instruments, Inc. (Winooski, VT, USA). RPMI-1640 was from Gibco (Waltham, MA, USA). FCS was from Sijiqing (Hangzhou, China). Tumor necrosis factor- $\alpha$ (TNF- $\alpha$ ), interleukin (IL)- $1 \beta$ and IL-6 ELISA kits were from eBioscience (San Diego, CA, USA). Transwell 24-well sets and 12- and 48-well plates were from Corning Inc. (Corning, NY, USA). Dextran T-500 and Percoll were from Pharmacia (Piscataway, NJ, USA). 2',7'-Dichlorofluorescein-diacetate (DCFH-DA) was from Nanjing Jiancheng Chemical Industrial Co., Ltd. (Nanjing, China). Anti-GAPDH antibody (ab9485) and anti-NF- $\mathrm{KB}$ p65 (ab16502) antibodies were from Abcam (Cambridge, UK). Horseradish peroxidase (HRP)-labeled secondary antibody was from Hangzhou Lianke Biology Technology Ltd. (Hangzhou, China). The ECL chemiluminescence detection kit was from Millipore (Burlington, MA, USA). Distilled water was produced in the EPED Superpure water purifying system (Nanjing EPED Science and Technology Development Co., Nanjing, China). All the reagents were at least analytical grade.

Extraction and purification of PTL. Fresh tubers of PT weighing $50 \mathrm{~g}$ were washed thoroughly with tap water and subsequently with distilled water. The combined roots and tubers were separated from the stems and leaves prior to crushing using a juice extractor to extract the juice and centrifugation for $20 \mathrm{~min}$ at $4^{\circ} \mathrm{C}$. The clear supernatant was dissolved with saturated $\left(\mathrm{NH}_{4}\right)_{2} \mathrm{SO}_{4}(\mathrm{pH}$ 7.0) and was centrifuged for $30 \mathrm{~min}$ at $4^{\circ} \mathrm{C}$. The precipitate was fully dissolved with $0.6 \mathrm{~mol} / 1\left(\mathrm{NH}_{4}\right)_{2} \mathrm{SO}_{4}(\mathrm{pH} 7.0)$ and centrifuged at a high speed. The resulting supernatant obtained was applied to a HiPrep $^{\mathrm{TM}}$ Phenyl FF $(10 \mathrm{ml})$ column. The mobile phase was a $0.6-0 \mathrm{~mol} / \mathrm{l}\left(\mathrm{NH}_{4}\right)_{2} \mathrm{SO}_{4}$ gradient at a flow rate of $1.4 \mathrm{ml} / \mathrm{min}$.
The main peak was collected and applied to a column of HiTrap $^{\mathrm{TM}} \mathrm{Q}$ FF. The column was eluted with a gradient of $0-0.4 \mathrm{~mol} / 1 \mathrm{NaCl}$ at a flow rate of $2.5 \mathrm{ml} / \mathrm{min}$. Finally, the main peak was desalted with $0.02 \mathrm{~mol} / \mathrm{l}$ Tris- $\mathrm{HCl}(\mathrm{pH} 8.0)$ buffer for lectin purification and subsequently freeze-dried.

Size exclusion chromatography-high-performance liquid chromatography (HPLC), ID SDS-PAGE and in-gel digestion. Purified lectin preparation was checked on an Agilent 1200 system equipped with a DAD detector using an Agilent Zorbax GF-450 column $(9.4 \times 250 \mathrm{~mm})$. The mobile phase was $0.1 \mathrm{~mol} / 1 \mathrm{phosphate}$ buffer at a flow rate of $1.5 \mathrm{ml} / \mathrm{min}$. PTL was also subjected to SDS-PAGE (pH 8.3), using a 15\% (w/v) acrylamide slab gel for subunit molecular mass determination. The sample was heated for $5 \mathrm{~min}$ in a boiling water bath. The gel was stained with silver nitrate. Molecular weights of the standard marker proteins were matched with that of the sample protein $(4.6-42.0 \mathrm{kDa})$ to determine the subunit molecular weight of PTL.

The 12-kDa protein band was destained with $400 \mu 1$ of $30 \%$ acetonitrile in $100 \mathrm{mM} \mathrm{NH}_{4} \mathrm{HCO}_{3}$, reduced with $10 \mu \mathrm{l}$ of $100 \mathrm{mM}$ dithiothreitol at $56^{\circ} \mathrm{C}$ for $30 \mathrm{~min}$, dehydrated with $100 \mu \mathrm{l}$ of acetonitrile, alkylated with $30 \mu \mathrm{l}$ of $200 \mathrm{mM}$ iodoacetamide at room temperature in the dark for $20 \mathrm{~min}$, dehydrated with $100 \mu \mathrm{l}$ of acetonitrile, and subsequently dried. In-gel tryptic digestion was carried out at $37^{\circ} \mathrm{C}$ for $20 \mathrm{~h}$ using a $10.0 \mathrm{ng} / \mathrm{ml}$ solution of sequencing grade-modified trypsin (Promega, Madison, WI, USA). Tryptic peptides resulting from the digestion were extracted with $100 \mu 1$ of $60 \%$ acetonitrile in $0.1 \%$ formic acid for $15 \mathrm{~min}$. The extraction was repeated 3 times. The extracted peptides were dried and reconstituted with 5\% acetonitrile and $0.1 \%$ formic acid in water.

LC-mass spectrometry (MS)/MS and database search. The extracted peptides were analyzed using an LC-LTQ system (LTQ VELOS, Thermo Finnigan, San Jose, CA, USA). Briefly, peptides were first enriched on a reverse-phase trap column (Zorbax 300SB-C ${ }_{18}$ peptide traps; Agilent Technologies, Wilmington, DE, USA) and subsequently eluted to an analytical column (RP- $\mathrm{C}_{18}, 0.15 \times 150 \mathrm{~mm}$; Column Technologies Inc., Lombard, IL, USA). The flow rate of the pump was $0.15 \mathrm{ml} / \mathrm{min}$. The mobile phases used for the reverse phase were (A) $0.1 \%$ formic acid in $84 \% \mathrm{ACN}$ and (B) $0.1 \%$ formic acid in water, $\mathrm{pH} 3.0$. The gradient started at $4 \%$ solvent $\mathrm{A}$, where it was held for $4 \mathrm{~min}$, went linearly to $50 \%$ solvent A in $15 \mathrm{~min}$, and subsequently went linearly to $100 \%$ solvent A in $3 \mathrm{~min}$. An electrospray ionization mass spectrometer was used for peptide detection. The positive-ion mode was employed and the spray voltage was set at $3.2 \mathrm{kV}$. The spray temperature was set at $200^{\circ} \mathrm{C}$ for peptides. Collision energy was set automatically by the LTQ system. The mass spectrometer was set as one full MS scan followed by $10 \mathrm{MS} / \mathrm{MS}$ scans on the most intense ions. Protein identification using MS/MS raw data was performed with the BioWorks Browser 3.3 (University of Washington, Seattle, WA, USA; licensed to Thermo Finnigan) searching program against the UniProt Arecaceae protein database. The protein identification criteria that were used were based on Delta $\mathrm{CN}(\geq 0.1)$ and Xcorr (one charge $\geq 1.9$, two charges $\geq 2.2$, three charges $\geq 3.75$ ). 
Isolation of mouse peritoneal macrophages. Animals were sacrificed and sterilized in $75 \%$ alcohol. Each mouse was injected intraperitoneally with $4 \mathrm{ml}$ of cold phosphate-buffered saline (PBS) and massaged softly for $3 \mathrm{~min}$. Harvested peritoneal fluid was centrifuged at $70 \mathrm{x}$ g for $4 \mathrm{~min}$ and the precipitate was dissolved and adjusted to $1 \times 10^{6}$ cells $/ \mathrm{ml}$ with RPMI-1640 containing 10\% fetal bovine serum (FBS). Peritoneal cells were subsequently cultured in a 48 -well plate and washed 3 times with cold PBS after incubation at $37^{\circ} \mathrm{C}$ for $2 \mathrm{~h}$. Macrophage purity was examined with non-specific esterase staining as $>98 \%$. The viability of cells was $>99 \%$, as determined by the trypan blue exclusion test.

Isolation of human venous blood neutrophils. Blood from healthy volunteers $(5 \mathrm{ml})$ was drawn into vacuum blood collection tubes containing EDTA-2Na. The blood was mixed with cold PBS and Dextran T-500 (1.5:1.5:1, v/v/v) at room temperature until sedimentation of the red blood cells. The supernatant was collected 30 min later and centrifuged at $110 \mathrm{x} \mathrm{g}$ for $10 \mathrm{~min}$. The precipitate was subsequently centrifuged together with $75 \%$ Percoll and $60 \%$ Percoll at $250 \mathrm{x}$ g for $20 \mathrm{~min}$. Following centrifugation, neutrophils were purified from the blood cells. This procedure usually produced a cell fraction containing over $99 \%$ neutrophils, as determined by quick Giemsa staining. The trypan blue exclusion test showed that the viability of cells was $>99 \%$ (21).

Neutrophil chemotaxis in vitro is induced by macrophages stimulated with PTL. To confirm that macrophages activated by PTL were involved in the recruitment of neutrophils, an in vitro chemotaxis experiment was conducted as follows: $100 \mu \mathrm{l}$ of the neutrophil suspension $\left(10^{6}\right.$ cells $\left./ \mathrm{ml}\right)$ was placed in the upper wells of a 24-well modified Corning Transwell set equipped with a polycarbonate filter ( $8 \mu \mathrm{m}$ pore size); in the lower wells, the protocol was set up either with D-Hanks or PTL $(50 \mu \mathrm{g} / \mathrm{ml}$ in D-Hanks)-treated fresh medium, or with D-Hanks or PTL (50 $\mu \mathrm{g} / \mathrm{ml}$ in D-Hanks)-treated pre-cultured macrophages $\left(10^{6}\right.$ cells $\left./ \mathrm{ml}\right)$.

Following Transwell plate incubation for $1.5 \mathrm{~h}$ at $37^{\circ} \mathrm{C}$ in $5 \% \mathrm{CO}_{2}$, the cells remaining in the upper wells were removed using cotton swabs and those retained on the lower side of the filter were stained with Giemsa staining. The number of neutrophils reaching the lower side of the filter was counted in 5 random fields using an electron microscope (objective, $\mathrm{x} 40$ ) for each set of wells.

Induction of the cytokines released from macrophage stimulated by different doses of PTL. Mouse macrophages were harvested with RPMI-1640, cultured in plastic dishes (48-wells of $500 \mu \mathrm{l}$ capacity), washed and replaced with $450 \mu \mathrm{l} /$ well fresh RPMI-1640 containing 10\% FBS prior to the experiment. The protocol for the assay of TNF- $\alpha$ and IL-1 $\beta$ was conducted using 6 groups (3 wells/group) of macrophages treated as follows: Group 1, $50 \mu \mathrm{l} /$ well PBS alone; and groups 2-6, $50 \mu \mathrm{l} /$ well PTL $(25,50,100,200$ and $400 \mu \mathrm{g} / \mathrm{ml})$. The protocol for the assay of IL-6 was conducted using 8 groups ( 3 wells/group) of macrophages treated as follows: Group 1,50 $\mu 1$ /well PBS alone; and groups 2-6, 50 $\mu \mathrm{l} /$ well PTL $(6.25,12.5,25,50,100,200$ and $400 \mu \mathrm{g} / \mathrm{ml})$. After $3 \mathrm{~h}$ of incubation, all the supernatants were harvested and stored at $-80^{\circ} \mathrm{C}$. The levels of TNF- $\alpha$, IL-1 $\beta$, IL-6 and nitric oxide (NO) released by macrophages were measured using ELISA kits according to the manufacturer's instructions.

Time curves of the cytokines released from macrophages stimulated by PTL. Mouse macrophages were harvested with RPMI-1640, cultured in plastic dishes (48-wells of $500 \mu \mathrm{l}$ capacity), washed and replaced with $450 \mu \mathrm{l} /$ well fresh RPMI-1640 containing 10\% FBS prior to the experiment. The protocol was conducted using 18 groups (3 wells/group) of macrophages treated half with $50 \mu \mathrm{l}$ of $100 \mu \mathrm{g} / \mathrm{ml}$ PTL and the others with $50 \mu \mathrm{l}$ of PBS as control groups. The incubating times were as follows: 0.5, 1, 1.5, 2, 2.5, 3, 6, 9 and $12 \mathrm{~h}$. After the incubation, all the supernatants were harvested and stored at $-80^{\circ} \mathrm{C}$. The levels of TNF- $\alpha$, IL- $1 \beta$, IL- 6 and NO released by macrophages were measured using the ELISA kits according to the manufacturer's instructions.

Measurement of intracellular reactive oxygen species (ROS) in macrophages stimulated by PTL. Intracellular ROS production was measured using DCFH-DA (22). DCFH-DA penetrates into cells and is hydrolyzed by intracellular esterase to the non-fluorescent DCFH, which can be rapidly oxidized to the highly fluorescent 2,7-dichlorofluorescein (DCF) in the presence of ROS. Peritoneal macrophages were seeded at $1 \times 10^{6}$ cells/well in 12 -well plates. PTL was dissolved and diluted in D-Hanks. Mouse macrophages were harvested with RPMI-1640, cultured in plastic dishes (48-wells of $500 \mu 1$ capacity), washed and replaced with $450 \mu \mathrm{l} /$ well fresh RPMI-1640 containing 10\% FBS prior to the experiment. Peritoneal macrophages were seeded at $1 \times 10^{6}$ cells/well in 12 -well plates. The protocol was conducted using 4 groups (3 wells per group) of macrophages treated as follows: Group 1, $50 \mu \mathrm{l} /$ well D-Hanks alone; and groups 2-4, $50 \mu \mathrm{l} /$ well PTL (25, 50 and $100 \mu \mathrm{g} / \mathrm{ml})$. Following stimulation and incubation with or without different treatments for $1 \mathrm{~h}$, the cells were treated with $4 \mu \mathrm{M}$ DCFH-DA at $37^{\circ} \mathrm{C}$ for $20 \mathrm{~min}$ and examined using a fluorescence microscope (Nikon, Tokyo, Japan) with an emission wavelength of $598 \mathrm{~nm}$. The fluorescence intensity was measured with a fluorescence microplate reader with an excitation wavelength of $420 \mathrm{~nm}$ and an emission wavelength of $560 \mathrm{~nm}$.

Western blotting of nuclear factor- $\kappa B(N F-\kappa B)$ p65 in cytoplasm and nucleus of macrophages stimulated by PTL. To confirm that pro-inflammation induced by PTL was associated with the $\mathrm{NF}-\kappa \mathrm{B}$ signaling pathway, the content of p65 in the cytoplasm and nucleus was analyzed by western blot analysis, which was conducted using 4 groups (3 wells/group) of macrophages treated as follows: Group 1, $50 \mu \mathrm{l} /$ well PBS alone; and groups 2-4, $50 \mu \mathrm{l} /$ well PTL $(12.5,25$ and $50 \mu \mathrm{g} / \mathrm{ml})$. After $0.5 \mathrm{~h}$ of incubation, the culture supernatant was discarded, and the macrophages were washed with PBS buffer. Subsequently, the cytoplasmic and nuclear proteins of the macrophages were extracted (23). The cytoplasmic and nuclear protein solutions were denatured by boiling at $100^{\circ} \mathrm{C}$ for $5 \mathrm{~min}$, mixed evenly with $5 \mathrm{X}$ bromophenol blue loading buffer, and were loaded (10 $\mu \mathrm{l}$ for each lane) onto $10 \%$ SDS polyacrylamide gel followed by electroblotting onto nitrocellulose membrane. Following blocking of the non-specific binding with 5\% non-fat milk (prepared in TBS containing $0.1 \%$ Tween-20) for 
$3 \mathrm{~h}$, the membrane was applied with antibodies against p65 and GAPDH, followed by incubation with HRP-conjugated anti-rabbit antibody. Subsequently, the protein was detected using an ECL chemiluminescence detection kit and cultured for $5 \mathrm{~min}$ in the dark. Densitometry was performed using the software Quantity One (Bio-rad).

SEM analysis of surface characteristic changes of macrophages stimulated by PTL. Mouse macrophages were harvested as indicated. For SEM, the cells were cultured on the sterile slides placed in 6-well plastic plates. The assay was performed with 5 groups ( 3 wells/group) of macrophages treated with $500 \mu 1$ of $6.25,12.5,50$ and $100 \mu \mathrm{g} / \mathrm{ml}$ PTL. All the supernatants were harvested following incubation for $0.5,1$ and $3 \mathrm{~h}$. Each slide was washed with cold PBS 3 times and was fixed with $2.5 \%$ glutaraldehyde overnight. Sample slides were prepared through sequential dehydration in ethanol $(30,50,70$, 80,90 and $100 \%$ ). The sample slides were subsequently coated with gold-palladium prior to SEM observation. The morphological changes of macrophages were evaluated by capturing images focusing on a single macrophage at (magnification, $\mathrm{x} 3,000-5,000)$.

Statistical analysis. The data are presented as mean \pm standard error of the mean and compared using t-test by SPSS (SPSS, Inc., Chicago, IL, USA). P $<0.05$ was considered to indicate a statistically significant difference.

\section{Results}

Extraction, purification andidentification of PTL. Hydrophobic interaction, ion exchange and desalting chromatographic steps were applied to purify PTL. The crude protein extract was eluted by hydrophobic interaction. The main peak was eluted with a linear gradient of $\mathrm{NaCl}(0-0.4 \mathrm{~mol} / \mathrm{l})$. A single peak on HPLC and a single band of $\sim 13 \mathrm{kDa}$ on SDS-PAGE (Fig. 1) were observed, suggesting that the isolated PTL was quite pure. Gel electrophoresis was combined with LC-MS/MS for the proteomic analysis of PTL. The 13-kDa band was subjected to in-gel trypsin digestion. The peptides extracted from each band were loaded to LC-MS/MS for protein identification. Through a protein database search, the 13-kDa band protein was identified as PTL, with the molecule matching those previously reported (24).

Effects of PTL on neutrophil chemotaxis mediated by macrophages. In order to investigate the involvement of macrophages in neutrophil infiltration induced by PTL treatment, neutrophil migration assay was used with a 24-well Transwell set. Compared to the control (D-Hanks) group, significantly more neutrophils were retained on the lower surface of the filter following treatment with PTL $\left(\mathrm{PTL}+\mathrm{M}_{\Phi}+\mathrm{D}-\mathrm{Hanks}\right)$. Macrophages untreated with PTL (D-Hanks+M ${ }_{\Phi}$ ) and the group in which PTL did not coexist with macrophages (D-Hanks+PTL) did not show any neutrophil chemotaxis (Fig. 2), therefore, PTL-stimulated neutrophil chemotaxis was mediated by macrophages.

Induction of the cytokines released from macrophages activated by different doses of PTL. Peritoneal macrophages were
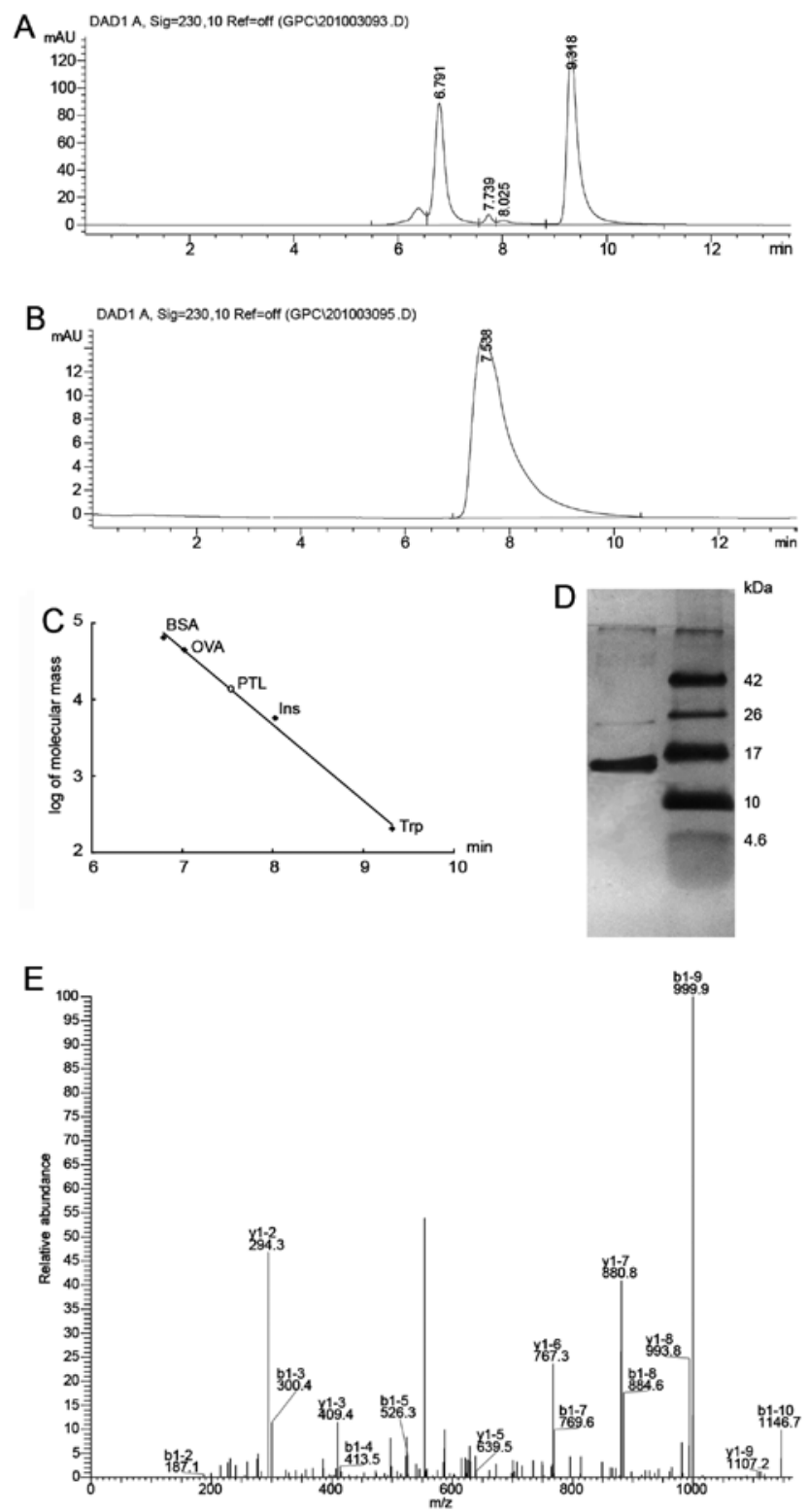

Figure 1. (A) Standard proteins analyzed by size-exclusion HPLC. Standard markers: Bovine serum albumin $(66.4 \mathrm{kDa})$, ovalbumin $(44 \mathrm{kDa})$, insulin $(5.7 \mathrm{kDa})$ and tryptophan $(0.2 \mathrm{kDa})$; (B) PTL by size-exclusion HPLC; (C) standard curve representing native molecular weight of PTL by size-exclusion HPLC; (D) 1D SDS-PAGE of PTL, pH 8.3 purified PTL using 15\% gel (run for $3 \mathrm{~h}$ at $16 \mathrm{~mA}$ ). The gels were stained with silver nitrate. (E) MS/MS of peptide 'GELIIKDDDFK' from PTL. HPLC, high-performance liquid chromatography; PTL, Pinellia ternata lectin; MS, mass spectrometry.

treated with indicated doses of PTL and the levels of released cytokines, such as TNF- $\alpha$, IL-1 $\beta$ and IL-6, were measured. PTL activated macrophages to release TNF- $\alpha$, IL-1 $\beta$ and IL-6 in a dose-dependent manner. Compared to the control group (PBS), the levels of TNF- $\alpha$, IL-1 $\beta$ and IL- 6 significantly increased following exposure of the macrophages to PTL (50, 100, 200 and $400 \mu \mathrm{g} / \mathrm{ml}$ ) for $3 \mathrm{~h}$ (Fig. 3). Notably, IL-6 was more prone to induction compared with TNF- $\alpha$ and IL- $1 \beta$.

Time curves of the cytokines released from macrophages activated by PTL. To confirm whether PTL could cause acute inflammation in animal models, macrophages were treated by PTL for different periods of time and the levels of cytokines, 

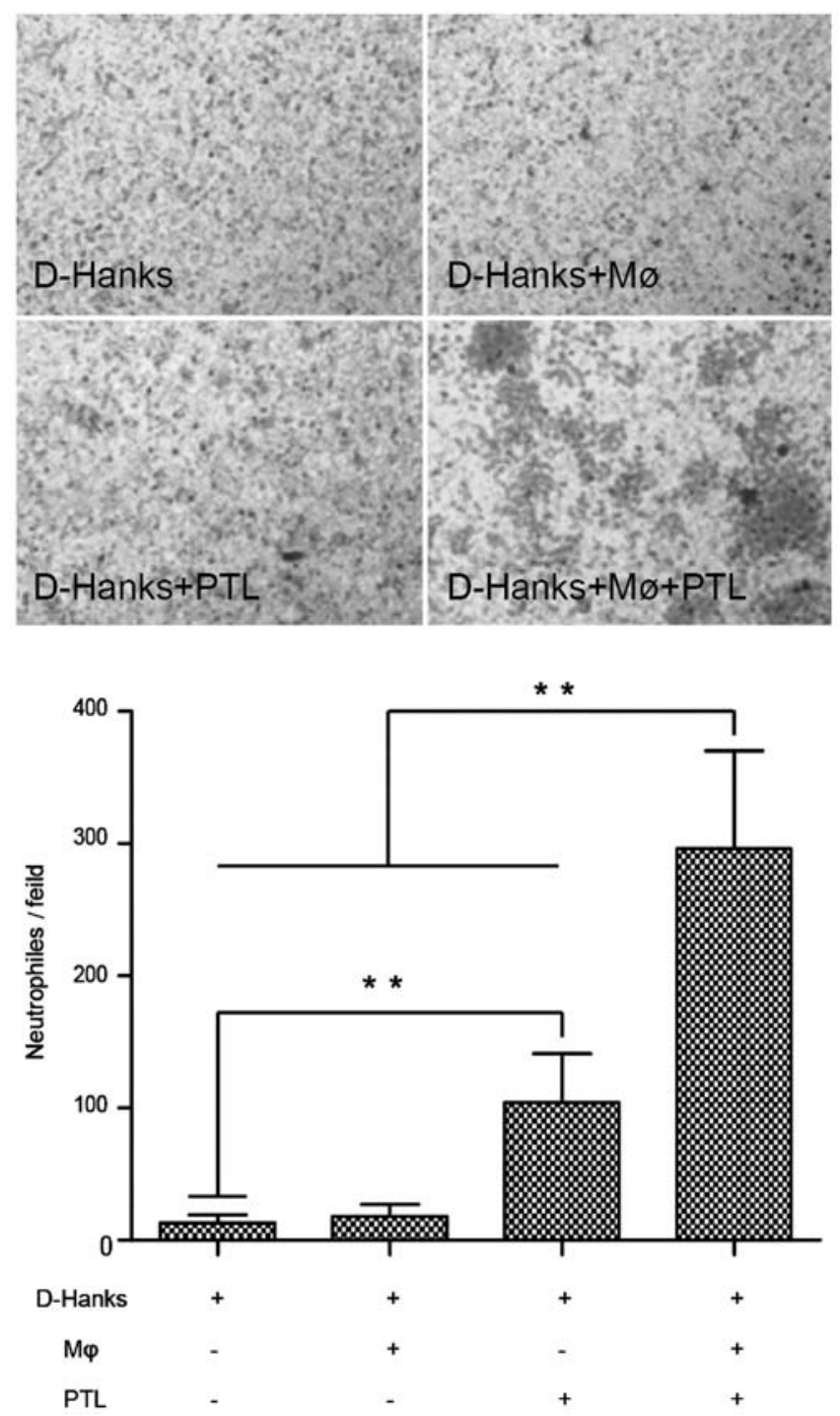

Figure 2. Neutrophil migration in vitro induced by PTL-stimulated macrophages. Neutrophil chemotaxis was evaluated in a 24-well Transwell set. PTL $(50 \mu \mathrm{g} / \mathrm{ml})$ showed neutrophil chemotaxis activity and PTL $+\mathrm{M}_{\Phi}$ significantly enhanced such effect. Results are mean \pm standard error of the mean $(n=5) .{ }^{* *} \mathrm{P}<0.01$ compared to D-Hanks or D-Hanks $+\mathrm{M}_{\Phi}$ (t-test). PTL, Pinellia ternata lectin.

TNF- $\alpha$, IL-1 $\beta$ and IL-6, were measured. As shown in Fig. 4, the levels of TNF- $\alpha$ and IL- $1 \beta$ significantly increased $1.5 \mathrm{~h}$ after stimulation compared to the control. The levels of TNF- $\alpha$ and IL- $1 \beta$ reached maxima after $3 \mathrm{~h}$ of treatment with PTL, and subsequently gradually decreased (Fig. 4A and B). The time curve of IL- 6 changed in a similar manner. In addition, PTL significantly increased the level of IL-6 starting from $1 \mathrm{~h}$ (Fig. 4C). Therefore, PTL may cause inflammation in macrophages at an early stage.

Effects of PTL on ROS overproduction by macrophages. To evaluate the effects of PTL on ROS production, macrophages were stimulated with different doses of PTL $(25,50$ and $100 \mu \mathrm{g} / \mathrm{ml}$ ) for $1 \mathrm{~h}$ and observed under an inverted fluorescence microscope following the addition of a fluorescent probe, DCFH-DA. The fluorescence intensity was measured with a fluorescence microplate reader. Compared with the D-Hanks group, elevating the PTL dose significantly increased
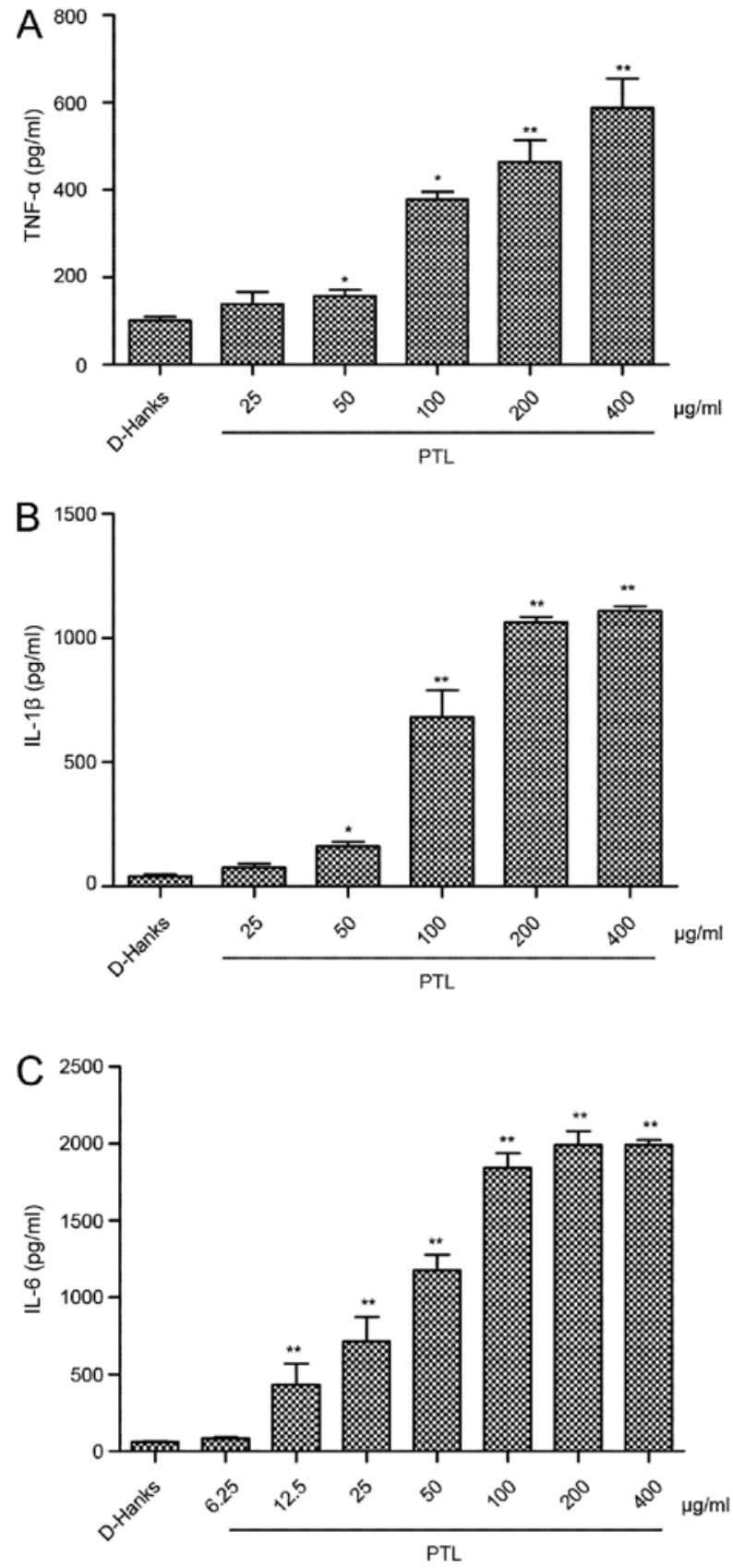

Figure 3. Induction of the cytokines released from macrophages activated by different doses of PTL. Cultured mouse resident macrophages were treated with PTL for $3 \mathrm{~h}$. PTL (50, 100, 200 and $400 \mu \mathrm{g} / \mathrm{ml})$ induced (A) TNF- $\alpha$ and (B) IL-1 $\beta$ dose-dependently in the supernatant. The level of (C) IL-6 was also dose dependent (PTL: 12.5, 25, 50, 100, 200 and $400 \mu \mathrm{g} / \mathrm{ml}$ ). Cytokine levels were measured by ELISA. Results are mean \pm standard error of the mean $(\mathrm{n}=3) .{ }^{*} \mathrm{P}<0.05,{ }^{* *} \mathrm{P}<0.01$ compared to phosphate-buffered saline (t-test). PTL, Pinellia ternata lectin; TNF, tumor necrosis factor; IL, interleukin.

the intracellular ROS contents (Fig. 5). Thus, PTL stimulated macrophages to undergo intense oxidative stress, releasing considerable ROS eventually.

Western blotting of $N F-\kappa B$ p65 in cytoplasm and the nucleus. Following stimulation with PTL $(5,12.5$ and $25 \mu \mathrm{g} / \mathrm{ml})$ for $0.5 \mathrm{~h}$, the content of $\mathrm{p} 65$ in the macrophage cytoplasm reduced compared with that of the blank group (Fig. 6B), however, this content in the macrophage nucleus markedly increased (Fig. 6A), all showing evident dose-effect 

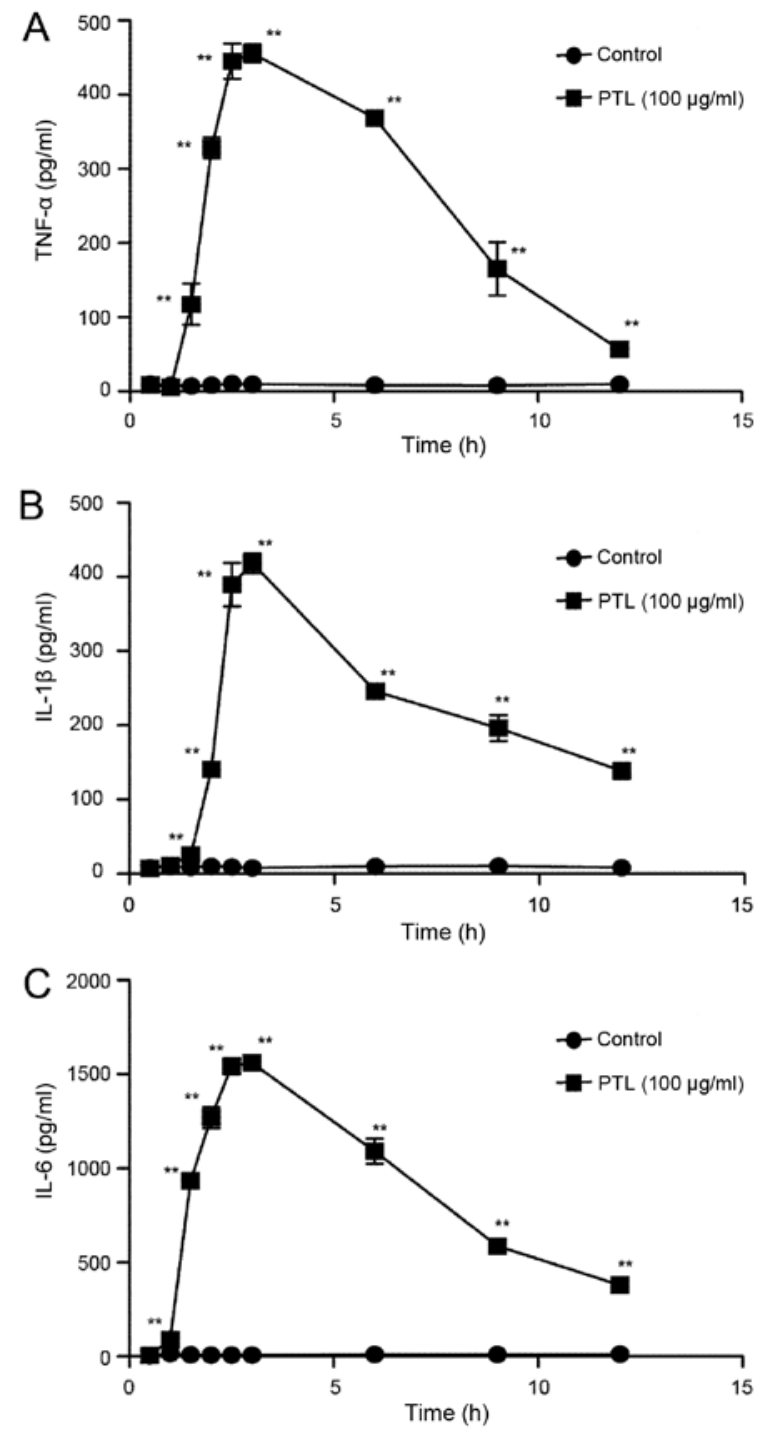

Figure 4. Time curves of the cytokines released from macrophages activated by PTL. The levels of PTL $(100 \mu \mathrm{g} / \mathrm{ml})$-induced cytokines significantly increased (A) TNF- $\alpha$, (B) IL- $1 \beta$ or $1 \mathrm{~h}$ (C) IL- $61.5 \mathrm{~h}$ following stimulation, with the maximal levels at $3 \mathrm{~h}$, and gradually returned to the contro level. Results are mean \pm standard error of the mean $(\mathrm{n}=3)$. ${ }^{*} \mathrm{P}<0.05,{ }^{* *} \mathrm{P}<0.01$ compared to phosphate-buffered saline (t-test). PTL, Pinellia ternata lectin; $\mathrm{TNF}$, tumor necrosis factor; IL, interleukin.

associations. Therefore, PTL stimulation caused transfer of p65 from the macrophage cytoplasm to the nucleus, which suggested that the inflammation induced by PTL-stimulated macrophage was associated with the $\mathrm{NF}-\kappa \mathrm{B}$ signaling pathway.

SEM analysis of surface characteristic changes of macrophages stimulated by PTL. The morphological changes of macrophages following treatment with PTL were observed using SEM. As shown in Fig. 4, the mouse peritoneal macrophages were normal at $0 \mathrm{~h}$ of PTL treatment. From $0.5 \mathrm{~h}$ of treatment, $6.25,12.5$ and $50 \mu \mathrm{g} / \mathrm{ml}$ PTL caused apparent wrinkles on the macrophage surface and more pseudopodia, accompanied by clear morphological changes. At 3 h, 50 and $100 \mu \mathrm{g} / \mathrm{ml}$ PTL evidently damaged or even destructed the macrophage surface (Fig. 7). Therefore, PTL at appropriate doses could induce the activation of macrophages, and at a high dose induced cell death.
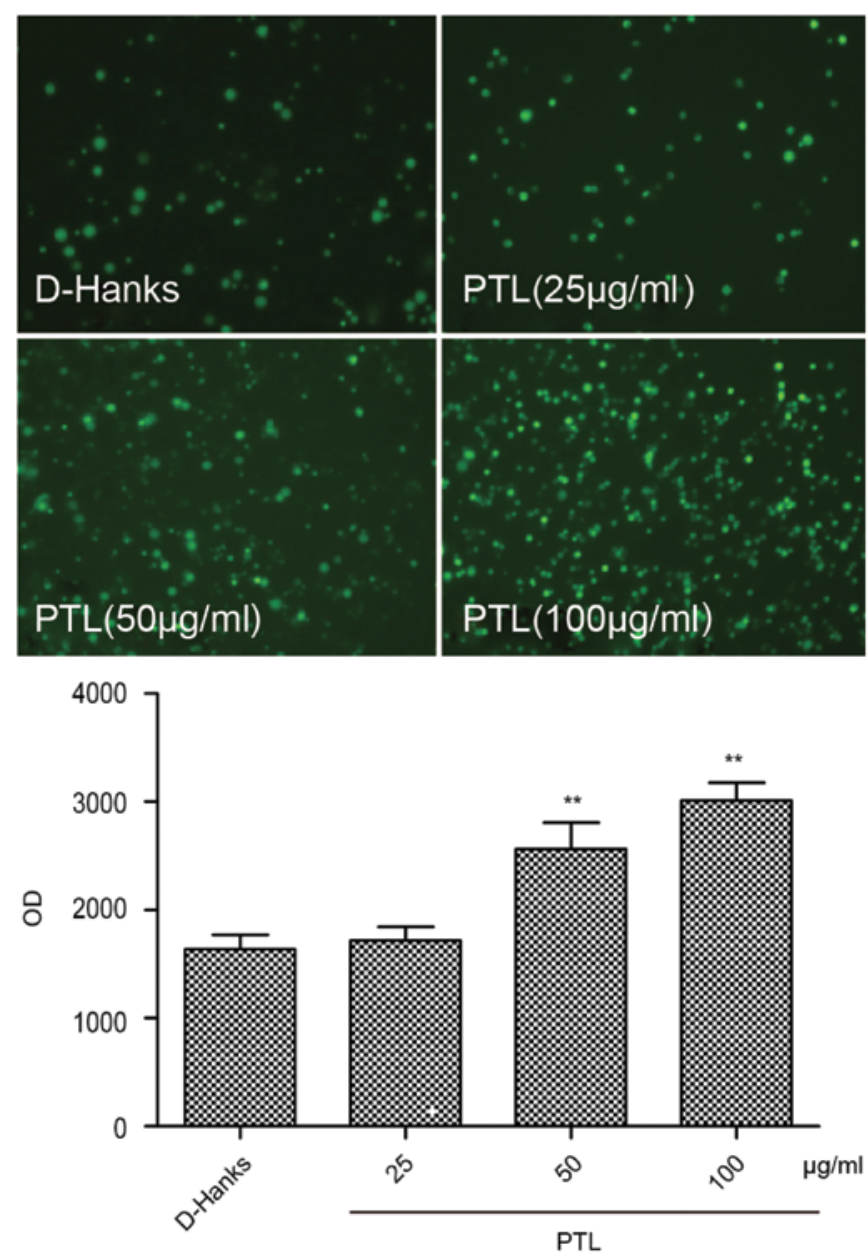

Figure 5. ROS production in vitro induced by PTL-stimulated macrophages. Compared with the D-Hanks group, elevating PTL dose (25, 50 and $100 \mu \mathrm{g} / \mathrm{ml}$ ) managed to significantly increase intracellular ROS contents. Results are mean \pm standard error of the mean $(n=3) .{ }^{* *} \mathrm{P}<0.01$ compared to D-Hanks (t-test). Images were captured on a fluorescence microscope at magnification, x200. ROS, reactive oxygen species; PTL, Pinellia ternata lectin; OD, optical density.

\section{Discussion}

The toxicity of lectins from plants has been widely reported in clinical and animal experiments. Despite numerous trials aiming to discover the mechanism of neutrophil infiltration involved in inflammation progression, the role of resident macrophages remains unclear.

Resident macrophages dominantly control such processes by targeting the stimuli, phagocytizing and producing chemotactic cytokines $(25,26)$. In the acute inflammatory response, neutrophil migration from venous blood to the affected sites involves complex processes between neutrophils, endothelial cells, macrophages and other immune cells.

Plant lectins, particularly monocot mannose-binding lectins, have shown pro-inflammatory effects. Vatairea macrocarpa lectin (VML), Pisum arvense lectin (PAL), Helianthus tuberosus lectin (HTL) and Dioclea rostrata lectin (DRL) induced acute inflammation through neutrophils migration in vivo, and injecting culture supernatants of DRA-stimulated macrophages in vivo significantly induced the release of TNF- $\alpha$, IL-1 $\beta$ and NO in the mouse peritoneal 


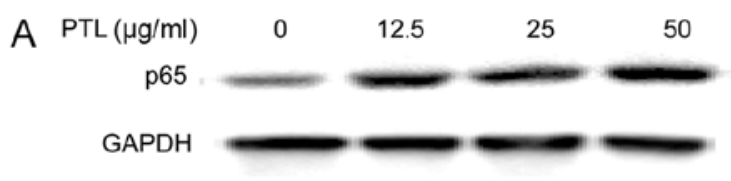

nuclei

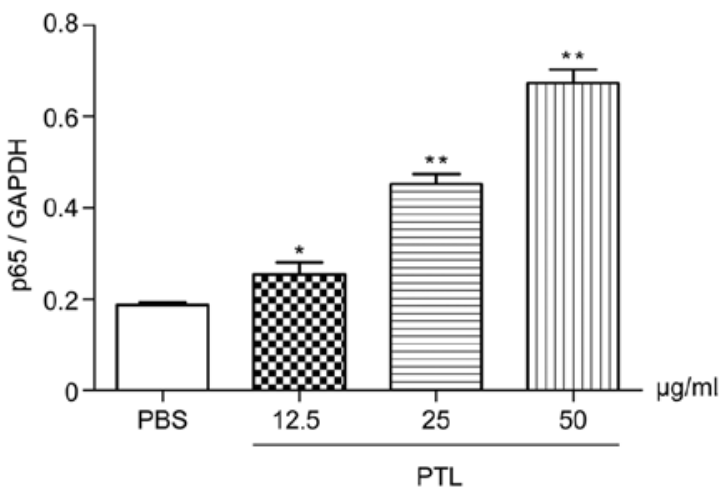

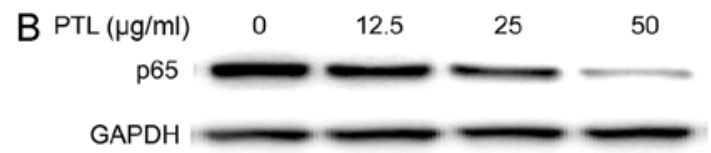

cytoplasm

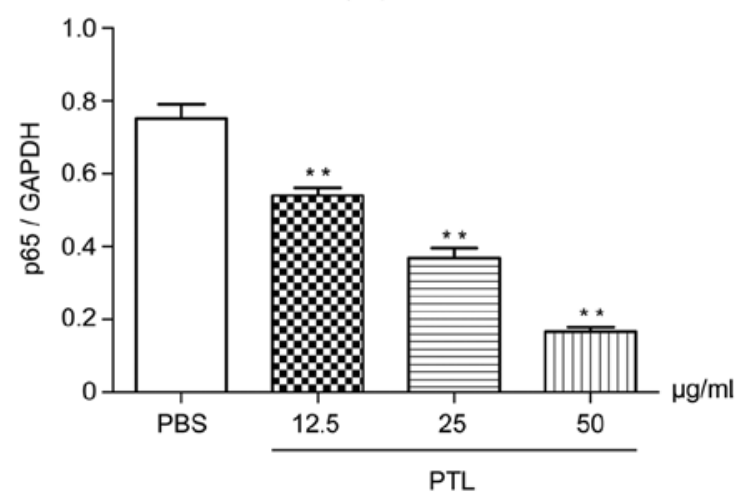

Figure 6. Following stimulation with 5, 10 and $20 \mu \mathrm{g} / \mathrm{ml}$ PTL for $0.5 \mathrm{~h}$, the content of p65 markedly increased in the (A) macrophage nucleus and reduced in the (B) cytoplasm. ${ }^{*} \mathrm{P}<0.05,{ }^{* *} \mathrm{P}<0.01$ compared to phosphate-buffered saline (t-test). PTL, Pinellia ternata lectin.

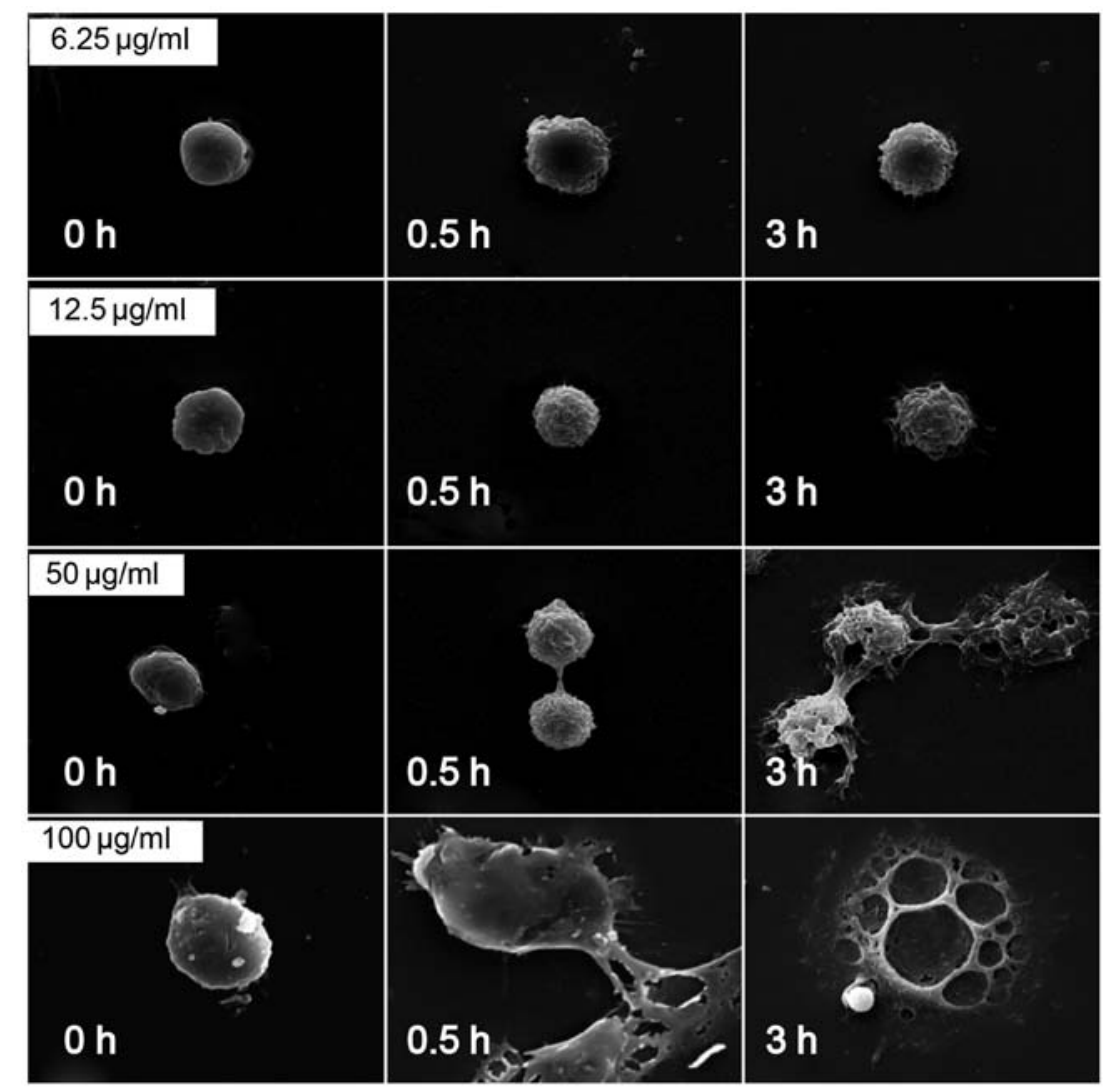

Figure 7. Surface morphological changes of macrophages stimulated by PTL. Images were captured on a scanning electron microscope at magnification, $5,000$. At $0 \mathrm{~h}$, normal macrophages were treated with PTL only; at $0.5 \mathrm{~h}, 6.25,12.5$ and $50 \mu \mathrm{g} / \mathrm{ml}$ PTL caused apparent wrinkles on the macrophage surface and more pseudopodia, accompanied by evident morphological changes; at $3 \mathrm{~h}, 50$ and $100 \mu \mathrm{g} / \mathrm{ml}$ PTL clearly damaged or even destructed the macrophage surface. PTL, Pinellia ternata lectin.

fluid (5,6,12-14,27). In our previous study, Arisaema erubescens lectin, which was derived from a plant in the Arisaema family, induced rat paw edema and in vivo neutrophil migration, possibly by releasing inflammatory mediators from macrophages (19).
In the present study, PTL stimulated chemotactic activity of neutrophils under the mediation of macrophages, and it also significantly elevated the production of cytokines (TNF- $\alpha$, IL-1 $\beta$ and IL-6) dose- and time-dependently, suggesting that PTL stimulated macrophages to induce inflammation. In 
addition, PTL also dose-dependently induced intracellular ROS. An intermediate amount of ROS triggers an inflammatory response through the activation of NF- $\mathrm{KB}$ (28). The present data showed that PTL caused transfer of p65 from the macrophage cytoplasm to the nucleus, which indicated that the NF- $\mathrm{KB}$ signaling pathway was activated. Therefore, PTL induced ROS overproduction and activated the NF- $\kappa B$ signaling pathway that subsequently released numerous pro-inflammatory cytokines, consistent with other results in the present study.

A high level of ROS also contributed to TNF-induced necrotic cell death in certain experiments $(29,30)$. In general, cell death includes two classic ways, apoptosis and necrosis, and the latter is described as a morphologically distinct form of cell death, which has traditionally been regarded as passive and unregulated $(31,32)$. In the present study, the PTL-induced cell damage was more similar to necrosis, rather than apoptosis, as indicated by the morphological changes. The SEM images showed that increasing the dose of PTL caused more pseudopodia, swelling and finally destructed the cell membrane as typical necrosis. Therefore, PTL at a high dose induced cell death possibly by overproducing ROS, and necrosis also triggered inflammation. Release of pro-inflammatory cytokines and neutrophil migration may be ascribed to ROS overproduction-induced activation of the NF- $\mathrm{kB}$ signaling pathway and necrosis.

PTL can induce inflammation, as well as cell death, and the latter aggravates the former. $P$. ternata has significant toxicity through the penetration of raphides. The findings of the present study provide valuable evidence for revealing the toxicity mechanism of $P$. ternata.

In conclusion, PTL showed pro-inflammatory activity in vitro, which induced neutrophil migration and pro-inflammatory cytokines release. PTL-stimulated macrophages exhausted the pro-inflammation effect, which was possibly associated with ROS overproduction, activating the NF- $\mathrm{KB}$ signaling pathway and necrosis-like damage on mouse peritoneal macrophages. These findings can be used to improve the understanding of the mechanisms involved in the inflammatory response of PTL.

\section{Acknowledgements}

The present study was supported by the National Nature Science Fund of China (grant no. 81173549), the Specialized Research Fund for the Doctoral Program of Higher Eucation (grant no. 20113237120010) and a project funded by the Priority Academic Program Development of Jiangsu Higher Education Institutions (PAPD). For other helpful assistance, the authors would like to thank Nanjing University of Chinese Medicine.

\section{References}

1. Peumans WJ and Van Damme EJ: Lectins as plant defense proteins. Plant Physiol 109: 347-352, 1995.

2. Moreira RA, Ainouz IL, De Oliveira JT and Cavada BS: Plant lectins, chemical and biological aspects. Mem Inst Oswaldo Cruz 86 (Suppl 2): 211-218, 1991

3. Cavada BS, Santos CF, Grangeiro TB, Nunes EP, Sales PV, Ramos RL, De Sousa FA, Crisostomo CV and Calvete JJ: Purification and characterization of a lectin from seeds of Vatairea macrocarpa Duke. Phytochemistry 49: 675-680, 1998.
4. Gabius HJ and Gabius S: Glycosciences: Status and perspectives Wiley-VCH, New York, p659, 2002.

5. Alencar VB, Brito GA, Alencar NM, Assreuy AM, Pinto VP, Teixeira EH, Souza EP, Debray H, Ribeiro RA and Cavada BS: Helianthus tuberosus agglutinin directly induces neutrophil migration, which can be modulated/inhibited by resident mast cells. Biochem Cell Biol 83: 659-666, 2005.

6. Mota MR, Criddle DN, Alencar NM, Gomes RC, Meireles AV, Santi-Gadelha T, Gadelha CA, Oliveira CC, Benevides RG, Cavada BS, et al: Modulation of acute inflammation by a chitin-binding lectin from Araucaria angustifolia seeds via mast cells. Naunyn Schmiedebergs Arch Pharmacol 374: 1-10, 2006.

7. Santos-de-Oliveira R, Dias-Baruffi M, Thomaz SM, Beltramini LM and Roque-Barreira MC: A neutrophil migration-inducing lectin from Artocarpus integrifolia. J Immunol 153: 1798-1807, 1994.

8. Assreuy AM, Shibuya MD, Martins GJ, De Souza ML, Cavada BS, Moreira RA, Oliveira JT, Ribeiro RA and Flores CA: Anti-inflammatory effect of glucose-mannose binding lectins isolated from Brazilian beans. Mediators Inflamm 6: 201-210, 1997.

9. Alencar NM, Teixeira EH, Assreuy AM, Cavada BS, Flores CA and Ribeiro RA: Leguminous lectins as tools for studying the role of sugar residues in leukocyte recruitment. Mediators Inflamm 8: 107-113, 1999.

10. Cavada BS, Barbosa T, Arruda S, Grangeiro TB and Barral-Netto M: Revisiting proteus: Do minor changes in lectin structure matter in biological activity? Lessons from and potential biotechnological uses of the Diocleinae subtribe lectins. Curr Protein Pept Sci 2: 123-135, 2001.

11. Alencar NM, Assreuy AM, Alencar VB, Melo SC, Ramos MV, Cavada BS, Cunha FQ and Ribeiro RA: The galactose-binding lectin from Vatairea macrocarpa seeds induces in vivo neutrophil migration by indirect mechanism. Int J Biochem Cell Biol 35: 1674-1681, 2003.

12. Assreuy AM, Alencar NM, Cavada BS, Rocha-Filho DR Feitosa RF, Cunha FQ, Calvete JJ and Ribeiro RA: Porcine spermadhesin PSP-I/PSP-II stimulates macrophages to release a neutrophil chemotactic substance: Modulation by mast cells. Biol Reprod 68: 1836-1841, 2003.

13. Alencar NM, Assreuy AM, Criddle DN, Souza EP, Soares PM, Havt A, Aragão KS, Bezerra DP, Ribeiro RA and Cavada BS: Vatairea macrocarpa lectin induces paw edema with leukocyte infiltration. Protein Pept Lett 11: 195-200, 2004.

14. Alencar VB, Assreuy AM, Alencar NM, Meireles AV, Mota MR, Aragão KS, Cajazeiras JB, Nagano CS, Brito GA, Silva LI, et al: Lectin of Pisum arvense seeds induces in vivo and in vitro neutrophil migration. J Pharm Pharmacol 57: 375-381, 2005.

15. McEver RP: Leukocyte-endothelial cell interactions. Curr Opin Cell Biol 4: 840-849, 1992.

16. Cronstein BN and Weissmann G: The adhesion molecules of inflammation. Arthritis Rheum 36: 147-157, 1993.

17. Malik AB and Lo SK: Vascular endothelial adhesion molecules and tissue inflammation. Pharmacol Rev 48: 213-229, 1996.

18. Alencar NM, Assreuy AM, Havt A, Benevides RG, de Moura TR, de Sousa RB, Ribeiro RA, Cunha FQ and Cavada BS: Vatairea macrocarpa (Leguminosae) lectin activates cultured macrophages to release chemotactic mediators. Naunyn Schmiedebergs Arch Pharmacol 374: 275-282, 2007.

19. Liu XQ, Wu H, Yu HL, Zhao TF, Pan YZ and Shi RJ: Purification of a lectin from Arisaema erubescens (Wall.) Schott and its pro-inflammatory effects. Molecules 16: 9480-9494, 2011.

20. Yu HL, Zhu FG and Wu G: Toxic proteins on Raphides from Pinellia ternata and Pinellia pedatisecta. Chin J Tradit Chin Med Pharm 26: 1037-1042, 2011.

21. Sawant KV, Cho H, Lyons M, Ly LH and McMurray DN: Guinea pig neutrophil-macrophage interactions during infection with Mycobacterium tuberculosis. Microbes Infect 12: 828-837, 2010.

22. Sánchez-Fidalgo S, da Silva MS, Cárdeno A, Aparicio-Soto M, Salvador MJ, Frankland Sawaya AC, Souza-Brito AR and de la Lastra CA: Abarema cochliacarpos reduces LPS-induced inflammatory response in murine peritoneal macrophages regulating ROS-MAPK signal pathway. J Ethnopharmacol 149: 140-147, 2013.

23. Kim MK, Chung SW, Kim DH, Kim JM, Lee EK, Kim JY, Ha YM, Kim YH, No JK, Chung HS, et al: Modulation of age-related NF-kappaB activation by dietary zingerone via MAPK pathway. Exp Gerontol 45: 419-426, 2010. 
24. Shangary S, Singh J, Kamboj SS, Kamboj KK and Sandhu RS Purification and properties of four monocot lectins from the family Araceae. Phytochemistry 40: 449-455, 1995.

25. Anstead GM, Chandrasekar B, Zhang Q and Melby PC: Multinutrient undernutrition dysregulates the resident macrophage proinflammatory cytokine network, nuclear factor-kappaB activation, and nitric oxide production. J Leukoc Biol 74: 982-991, 2003.

26. Silva MT: When two is better than one: Macrophages and neutrophils work in concert in innate immunity as complementary and cooperative partners of a myeloid phagocyte system. J Leukoc Biol 87: 93-106, 2010.

27. Alencar VB, Alencar NM, Assreuy AM, Mota ML, Brito GA, Aragão KS, Bittencourt FS, Pinto VP, Debray H, Ribeiro RA, et al: Pro-inflammatory effect of Arum maculatum lectin and role of resident cells. Int J Biochem Cell Biol 37: 1805-1814, 2005.
28. Gloire G, Legrand-Poels S and Piette J: NF-kappaB activation by reactive oxygen species: Fifteen years later. Biochem Pharmacol 72: 1493-1505, 2006.

29. Kim YS, Morgan MJ, Choksi S and Liu ZG: TNF-induced activation of the Nox1 NADPH oxidase and its role in the induction of necrotic cell death. Mol Cell 26: 675-687, 2007.

30. Han J, Zhong CQ and Zhang DW: Programmed necrosis: Backup to and competitor with apoptosis in the immune system. Nat Immunol 12: 1143-1149, 2011.

31. Kung G, Konstantinidis $\mathrm{K}$ and Kitsis RN: Programmed necrosis, not apoptosis, in the heart. Circ Res 108: 1017-1036, 2011.

32. McCall K: Genetic control of necrosis - another type of programmed cell death. Curr Opin Cell Biol 22: 882-888, 2010. 